\title{
The immediate postoperative complications and outcomes of kidney transplantation in children
}

\author{
M A M Faizal ${ }^{1}$, M M E D Dissanayake ${ }^{2}$, D Withanawasam ${ }^{2}$, D M A U K Dissanayake ${ }^{2}$, C K Abeysekera $^{3}$, \\ A Abeygunawardana ${ }^{4}$, M. D. Lamawansa ${ }^{5}$, C. D. A. Goonasekera ${ }^{6}$
}

Sri Lanka Journal of Child Health, 2012; 41(2): 65-70

\begin{abstract}
Objective: To evaluate the preoperative status of children admitted for renal transplantation, and their supportive care, complications and outcomes during the immediate postoperative period in the intensive care unit (ICU).
\end{abstract}

Design: Prospective observational study

Setting: ICU, Teaching Hospital, Peradeniya (THP)

Patients: Children who underwent renal transplantation at THP from July 2004 to October 2008

Measurements: Data regarding preoperative status and postoperative ICU complications was recorded in an Excel work sheet.

Results: Of 28 recipients of kidney transplantation at this centre during the specified period, 19 were male with a mean age of 9.6 (range 2-16) years. The commonest cause of end stage renal disease (ESRD) was obstructive uropathy $(28.6 \%)$. All received live donor transplantation. The mean $( \pm \mathrm{SD})$ pre-transplant haemoglobin $(\mathrm{Hb})$ and blood urea were $9.28 \pm$ $2.42 \mathrm{~g} / \mathrm{dl}$ and $21.97 \pm 10.17 \mathrm{mmol} / \mathrm{L}$ respectively. Of the patients $78.5 \%$ did not meet the minimum satisfactory $\mathrm{Hb}$ levels. Pre-operatively, $68.4 \%$ of the patients were hypertensive in spite of $18(64.3 \%)$ of them being on regular antihypertensive treatment. One patient $(3.6 \%)$ had haemodialysis (HD), 8 (28.6\%) had peritoneal dialysis (PD) and 2 (7.1\%) had had

Consultant Paediatric Intensivist, Paediatric
Intensive Care Unit, Sirimavo Bandaranaike
Specialized Hospital for Children, Peradeniya,
${ }^{2}$ Temporary Lecturer, Department of
Anaesthesiology, ${ }^{3}$ Professor in Paediatrics,
${ }^{4}$ Professor \& Head, Department of Paediatrics,
${ }^{5}$ Professor \& Head, Department of Surgery,
${ }^{6}$ Professor of Anaesthesiology, Faculty of Medicine,
University of Peradeniya

(Received on 26 November 2010: Accepted after revision on 12 July 2011) both prior to transplant. Seventeen $(60.7 \%)$ were preemptive transplants. The mean $( \pm \mathrm{SD})$ creatinine and creatinine clearance were $460.91 \pm 261.55 \mathrm{micromol} / \mathrm{L}$ and $22.89 \pm 25.98 \mathrm{ml} / \mathrm{min} / 1.73 \mathrm{~m}^{2}$ respectively. Mean $( \pm \mathrm{SD})$ duration of mechanical ventilation during the immediate postoperative period was $4.88 \pm 2.80$ days while the mean $( \pm \mathrm{SD})$ ICU stay was $6.44 \pm 3.35$ days. Postoperative ICU complications occurred in $75 \%$ of transplant recipients. Hypertension (46\%), metabolic complications such as acidosis, hyperglycaemia, hypocalcaemia, hyponatraemia $(32 \%)$, heart failure $(29 \%)$, convulsions $(25 \%)$ and sepsis $(25 \%)$ were the more common. Post-transplant creatinine and creatinine clearance were $60.69 \pm 31.19 \mathrm{micromol} / \mathrm{L}$ and $114 \pm 48 \mathrm{ml} / \mathrm{min} / 1.73 \mathrm{~m}^{2}$ respectively. No deaths or lost grafts were reported during the study period.

Conclusion: Kidney transplantation in the current context warrants a significant duration of ICU therapy postoperatively in children.

(Key words: Paediatric renal transplantation; complications; intensive care)

\section{Introduction}

Renal transplantation is the treatment of choice for chronic kidney disease (CKD) patients progressing to end stage renal disease (ESRD). It improves the quality of life ${ }^{1}$ and reduces medical expenses ${ }^{2}$ whilst preventing unnecessary early deaths ${ }^{3}$.

Recent advances in surgery, anaesthesia, postoperative care, immunosuppression and antimicrobial prophylaxis have made renal transplantation a safe procedure in children ${ }^{4}$. The main goals of postoperative care are to ensure stable haemodynamics providing optimal perfusion for the newly transplanted kidney along with good analgesia during the recovery period ${ }^{5}$. In Sri Lanka, due to the non availability of optimal end stage renal care, a majority of paediatric kidney transplant recipients have cardiovascular, haematological, respiratory and metabolic problems of long standing ESRD at presentation for surgery. These factors not only increase the complexity of anaesthesia and pain 
management but also adversely affect the posttransplant outcome.

Teaching Hospital Peradeniya (THP) is the first centre in Sri Lanka which initiated and engaged in a regular paediatric kidney transplantation programme. In contrast to most paediatric kidney transplant centres in the world, almost all paediatric kidney transplant recipients at THP needed admission to the intensive care unit (ICU) for postoperative care. In this prospective study we have analyzed the preoperative status of these children, postoperative intensive care and complications.

\section{Objectives}

- To evaluate the preoperative status of children admitted for renal transplantation.

- To evaluate their ICU stay with reference to immediate postoperative complications, duration of mechanical ventilation and outcome at discharge from the ICU.

\section{Method}

A prospective observational study was carried out at the ICU, THP from July 2004 to October 2008 on all children who underwent renal transplantation at THP during the study period. Required data of these children was recorded in an Excel work sheet. The preoperative body weight, haemoglobin, blood urea postoperative duration of mechanical ventilation, ICU stay, complications and the outcome at discharge from the ICU were recorded.

\section{Results}

\section{Demographic data}

Twenty eight children (19 male) who underwent kidney transplantation at THP between July 2004 and October 2008 were analyzed (Figure 1).

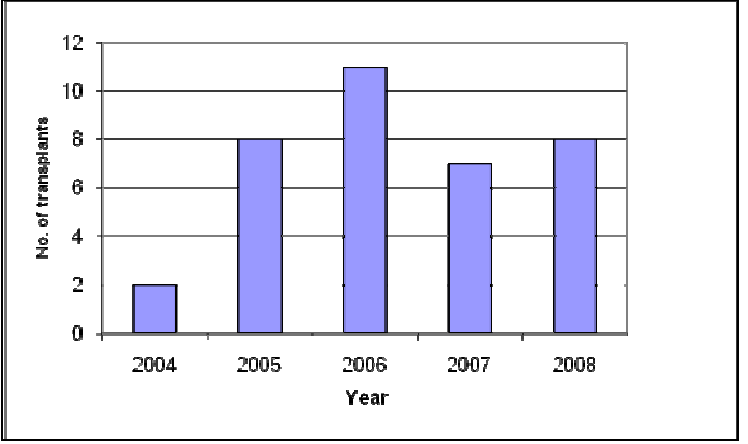

Figure 1: Annual rate of paediatric kidney transplantation at TH Peradeniya
Their mean age was 9.6 years (range $2-16$ ). The mean $( \pm \mathrm{SD})$ body weight was $20.6 \mathrm{~kg}( \pm 9.50)$. In $28.6 \%$ ESRD was due to posterior urethral valves associated obstructive uropathy. All received a live donor transplant.

\section{Preoperative status}

The mean $( \pm$ SD) pre-transplant haemoglobin was $9.28 \pm 2.42 \mathrm{~g} / \mathrm{dl}$ and mean $( \pm \mathrm{SD})$ blood urea was $21.97 \pm 10.17 \mathrm{mmol} / \mathrm{L}$. Only one patient had severe uraemia as defined by blood urea $>28.6 \mathrm{mmol} / \mathrm{L}$ or BUN $>80 \mathrm{mg} / \mathrm{dl}$ but without any pleural and pericardial effusions. Preoperatively, $68.4 \%$ of the patients were hypertensive despite 18 (64.3\%) being on regular antihypertensive treatment (Table 1). More than half were pre-emptive transplants. Among the others, peritoneal dialysis (PD) was commoner than haemodialysis (HD) and 7.1\% had had both HD and PD prior to transplant (Table 1).

\section{Table 1}

Preoperative status in the transplant cohort

\begin{tabular}{|l|c|}
\hline \multicolumn{1}{|c|}{ Parameters } & Number (\%) \\
\hline On treatment for hypertension & $18(64.3)$ \\
\hline Pre emptive transplants & $17(60.7)$ \\
\hline Haemodialysis (HD) & $01(3.6)$ \\
\hline Peritoneal Dialysis & $08(28.6)$ \\
\hline HD/PD & $02(7.1)$ \\
\hline
\end{tabular}

\section{Postoperative care}

All children were admitted to the ICU for postoperative mechanical ventilation following transplantation. The mean $( \pm \mathrm{SD})$ duration of mechanical ventilation was $4.88 \pm 2.8$ (range 2-14 days) while the mean $( \pm$ SD) ICU stay was $6.44 \pm 3.35$ (range 2-33) days.

The occurrence of postoperative complications in the ICU was 75\% (Table 2). Hypertension, metabolic derangements (hyperglycaemia, hypocalcaemia, acidosis, hyponatraemia) heart failure, convulsions and sepsis were the commoner problems. Bleeding diathesis, transplant kidney failure caused by delayed graft function needing dialysis, pulmonary oedema and acidosis, acute exacerbation of asthma, disseminated intravascular coagulation (DIC), lung collapse, paralytic ileus and cyclosporine toxicity were among the other complications (Table 2) and $7 \%$ needed additional rejection therapy. Neither graft loss nor deaths were reported amongst this cohort of post renal transplant patients during the perioperative period. 
Table 2

Post operative complications during ICU stay

\begin{tabular}{|l|c|}
\hline Complication & Number (\%) \\
\hline Hypertension & $13(46)$ \\
\hline Metabolic derangements & $09(32)$ \\
\hline Heart failure & $08(29)$ \\
\hline Convulsions & $07(25)$ \\
\hline Sepsis & $07(25)$ \\
\hline Bleeding diathesis & $05(18)$ \\
\hline Dialysis & $04(14)$ \\
\hline $\begin{array}{l}\text { Surgical causes (Re-exploration, } \\
\text { paralytic ileus) }\end{array}$ & $02(7)$ \\
\hline Pulmonary oedema & $01(3)$ \\
\hline $\begin{array}{l}\text { Transplant kidney failure } \\
\text { (delayed graft function) }\end{array}$ & $01(3)$ \\
\hline DIC & $01(3)$ \\
\hline Cyclosporine toxicity & $01(3)$ \\
\hline
\end{tabular}

\section{Discussion}

Renal transplant recipients constitute a high risk population peri-operatively due to the increased prevalence of cardiovascular disease, fluid and electrolyte abnormalities, bacterial infections, haematologic abnormalities, neurological disorders and gastrointestinal bleeding secondary to $\mathrm{CKD}^{6}$. As a consequence, these patients are prone to develop multi-organ failure and other complications in the immediate postoperative period.

Not so long ago paediatric transplantation was associated with poorer outcomes when compared to adults $^{7,8}$. Several factors were thought to be responsible for poorer outcomes in paediatric patients. These include differences in the aetiology of the renal failure, age related immune hyperactivity ${ }^{9}$ and increased risk of graft hypoperfusion injury as a result of the relative disparity between the donor and recipient kidney sizes ${ }^{10}$. However, more recent studies show renal transplantation becoming a more predictable procedure even in paediatric patients due to the advances in surgery, anaesthesia, immunosuppression and antimicrobial prophylaxis ${ }^{4}$.

For better outcomes in renal transplantation, it is necessary to optimize medical conditions associated with long-term renal impairment prior to surgery. Anaemia, high blood urea and hypertension are well recognized preoperative problems amongst our cohort. At present there is no clear evidence as to what the target $\mathrm{Hb}$ concentration for patients who undergo kidney transplant should be. The EBPG $^{11}$ and the NKF-DOQI ${ }^{\mathrm{TM}}$ Guidelines for the treatment of anaemia of $\mathrm{CKD}^{12}$ establish a minimum $\mathrm{Hb}$ concentration of $11 \mathrm{~g} / \mathrm{dl}$. In our study, 4 (14.28\%) patients had undergone renal transplantation with severe anaemia $(\mathrm{Hb}<7 \mathrm{~g} / \mathrm{dl})$. Hb levels of $78.5 \%$ of the patients did not meet minimum satisfactory level as recommended by the EBPG the NKF-DOQI ${ }^{\mathrm{TM}}$ and UK Renal Association ${ }^{13}$ guidelines.

In our study population the incidence of cardiac failure was unacceptably high (29\%). In a similar study conducted in Germany, the incidence of cardiac failure was only $1 \%$. The high prevalence of anaemia in the preoperative period has significantly increased the risk of developing cardiac failure in our study $(\mathrm{p}=0.0056 ; \mathrm{p}<0.01)$. Other factors such as poor preoperative blood pressure control, fluid overload combined with added side effects of cyclosporine and steroids would have also contributed. Unfortunately, preoperative cardiac function was not assessed in these patients due to unavailability of paediatric cardiology services at the transplant centre.

Hypertension is a serious complication in children after renal transplantation; it is an important risk factor not only for graft loss but also for cardiovascular morbidity and mortality of renal transplant recipients. The aetiology of post-transplant hypertension is multi-factorial: pre-transplant hypertension, damaged native kidneys, immunosuppressive therapy (steroids, cyclosporine, tacrolimus), renal graft artery stenosis and chronic allograft nephropathy are the commoner causes. Target blood pressure in children should be lower than the $90^{\text {th }}$ percentile for normal values adjusted for age, gender and height or 130/80 $\mathrm{mm} \mathrm{Hg}$, whichever is lower ${ }^{12}$. In our study population, $18(64.3 \%)$ of the patients had uncontrolled blood pressure preoperatively in spite of them being on regular antihypertensive treatment. Forty six percent of the study population developed hypertension during the ICU stay postoperatively, requiring multiple antihypertensive therapies including intravenous infusion of antihypertensive medications. On long term follow up, the prevalence of post-transplant hypertension ranges between $60-90 \%$ depending on the method of BP measurement and definition of hypertension. Left ventricular hypertrophy $(\mathrm{LVH})$ is frequent in end-organ damage in hypertensive children after renal transplantation occurring in 50$80 \%$ of them ${ }^{14}$. The authors would like to emphasize the fact that the apparent low prevalence of post-renal 
transplant hypertension in our study population could be misleading as we have only analyzed the immediate post transplant period; long term follow up is recommended to determine the prevalence of hypertension and the effect of pre-transplant hypertension on development of post transplant hypertension. In our cohorts, statistical analysis did not reveal preoperative hypertension as a risk factor for development of post-transplant hypertension $(p=0.089 ; p>0.05)$.

Dialysis also increases morbidity in these patients as it is associated with cardiovascular damage, impaired cognitive development and retardation of growth ${ }^{15-18}$. Pre-emptive kidney transplantation will prevent dialysis-associated morbidity and may therefore be preferable in children with $\mathrm{ESRD}^{19}$. However, nearly $40 \%$ of the recipients in our study had undergone either $\mathrm{PD} / \mathrm{HD}$ or both before transplantation indicating significant delays in processing them to be kidney transplant recipients. In similar studies the prevalence of pre-emptive transplant ranged from 20$28 \%{ }^{20,21}$. This figure is quite satisfactory compared to developed countries. Only one patient had had severe uraemia (blood urea $>28.6 \mathrm{mmol} / \mathrm{L}$ or BUN $>80 \mathrm{mg} / \mathrm{dl}$ ) even though the mean blood urea level was well above the norm for such ESRD children. Of those children receiving dialysis prior to transplantation, the majority, particularly infants and young children, received peritoneal dialysis, contrasting sharply with the adult experience where haemodialysis is the primary mode of therapy.

Paediatric transplantation activity in the developing world is limited to older children using mostly living related parental donors. High rejection and infection rates result in poor patient and graft survival ${ }^{22}$. In addition to providing good analgesia, the postoperative care of renal transplant recipients includes establishment of haemodynamic stability, maintaining adequate perfusion of the newly transplanted kidney and prevention and treatment of any possible complications due to fluid imbalance, electrolyte imbalance or myocardial weakness. In our series all patients required admission to ICU immediately after transplantation, although this is not a must in centres providing better ESRD care. In a similar series to ours, a children's hospital in Germany admitted all its renal transplant recipients to the ICU immediately after the surgery ${ }^{23}$. However, their average ICU stay for children aged less than 3 years was 2 days and for children older than 3 years was 1 day, which is much shorter than in our series (mean 6.44 \pm 3.35 (range 2- 33) days). On the other hand, adult renal transplant recipients are admitted to ICU postoperatively only if they have specific medical problems or complications ${ }^{11}$. In a developing country like ours, paediatric kidney transplant recipients should be expected to need ICU care postoperatively due to their preoperative medical problems and nutritional status. This is also justified by the limited number of experienced staff and facilities available in a general surgical or medical ward. It also appears that our paediatric population seems to need a longer period of postoperative mechanical ventilation (2-14 days) compared to statistics of the more advanced centres in the world (only 4-8 hours) where they electively ventilated all paediatric renal transplant recipients ${ }^{23}$.

Although the types of ICU complications were comparable with other available studies ${ }^{5,6,23,24}$, the incidence of convulsions is relatively higher in our study group compared to the other studies. This may have been contributed to by the cyclosporine toxicity (as less facilities for frequent monitoring of levels), hypertensive encephalopathy and cerebral oedema resulting from reverse osmosis due to the rapid reduction of a very high blood urea level. In our series we have confirmed cyclosporine toxicity in one patient but non availability of facilities to measure cyclosporine levels frequently may have led to many other missed cases.

We also seem to encounter a higher incidence of sepsis amongst these patients postoperatively in the ICU. Higher incidence of bleeding tendency can also be explained by the preexisting medical condition causing liver congestion and other haematological abnormalities. However, surgical reasons may also have contributed here. Hyperglycaemia is common but it is not a significant problem since it is transient.

Despite having limited facilities for the management of complicated patients, longer ICU stay with prolonged mechanical ventilation and poor preoperative general condition, we are glad that no child died and no graft was lost in the ICU postoperatively. This reflects good practices that one can adopt in the intensive care unit to achieve the goals.

\section{Conclusions}

- Kidney transplantation in the current context warrants a significant duration of ICU therapy postoperatively in children.

- Although the duration of intensive care stay and mechanical ventilation were prolonged in our cohorts, no loss of graft or death was recorded during the study period. 


\section{Recommendations}

Better clinical care for children with chronic kidney disease progressing to ESRD along with optimization of preoperative preparation for renal transplantation as well as developing facilities such as dedicated paediatric renal transplant centre and paediatric critical care services are recommended to minimize the complications of paediatric renal transplant programme at the THP.

\section{References}

1. Simmons RG, Abress L. Quality-of-life issues for end-stage renal disease patients. American Journal of Kidney Disease 1990; 15: 201-8.

2. Eggers P. Comparison of treatment costs between dialysis and transplantation. Seminars in Nephrology 1992; 12: 284-9.

3. Wolfe RA, Ashby VB, Milford EL et al. Comparison of mortality in all patients on dialysis, patients on dialysis awaiting transplantation, and recipients of a first cadaveric transplant. New England Journal of Medicine 1999; 341:1725-30. http://dx.doi.org/10.1056/NEJM1999120234123 $\underline{03}$

4. Della Rocca G, Costa MG, Bruno $\mathrm{K}$ et al. Paediatric renal transplantation: anaesthesia and perioperative complications. Pediatric Surgery International 2001; 17: 175-9. http://dx.doi.org/10.1007/s003830000486

5. Sahajananda H, Punithavathy J. Renal transplantation with and without epidural analgesia - A review of 6 years of experience. Indian Journal Anaesthesia 2006; 50(3): 187-92.

6. Sadaghdar H, Chelluri L, Bowles AS. Outcome of renal transplant recipients in the ICU. Chest 1995; 107:1402-5

http://dx.doi.org/10.1378/chest.107.5.1402

7. Garcia C, Barros V, Schneider L et al. Renal transplantation in children less than 6 years of age. Transplantation Proceedings 2001; 33: 3595-6. http://dx.doi.org/10.1016/S0041-1345(01)02546$\underline{5}$
8. Akpek E, Kayhan Z, Kayan H et al. Epidural anaesthesia for renal transplantation: a preliminary report. Transplantation Proceedings 1999; 31: 3149-50. http://dx.doi.org/10.1016/S0041-1345(99)00761$\underline{7}$

9. Ettenger RB, Bliffedl $\mathrm{C}$, Prince $\mathrm{H}$ et al. The paediatric nephrologists in dilemma: growth after renal transplantation and its interaction with age as a possible immunologic variable. Journal of Paediatrics 1987; 111: 1022-5. http://dx.doi.org/10.1016/S0022-3476(87)80049$\underline{5}$

10. Ettenger RB. Children are different: the challenges of pediatric renal transplantation. American Journal of Kidney Disease 1992; 20: 668-72.

11. European best practice guidelines for the management of anemia in patients with chronic renal failure. Nephrol Dial Transplant 1999; 14 Suppl 5: 1-50.

12. National Kidney Foundation: K/DOQI Work Group. NKF-DOQI clinical practice guidelines for the treatment of anaemia of chronic renal failure. Am $\quad J$ Kidney Dis 1997; 30 Suppl 3: S192-S240.

13. Renal Association and Royal College of Physicians of London. Treatment of adults and children with renal failure. Standards and Audit Measures $3^{\text {rd }}$ ed. London, UK: Renal Association and Royal College of Physicians of London, 2002.

14. Tomá, Seeman. Hypertension in Children after Renal Transplantation Current Hypertension Reviews, 2007; 3: 59-68. http://dx.doi.org/10.2174/157340207779815545

15. Groothoff JW, Grootenhuis M, Dommerholt A et al. Impaired cognition and schooling in adults with end stage renal disease since childhood. Archives of Disease in Childhood 2002; 87: 3805. http://dx.doi.org/10.1136/adc.87.5.380 
16. Groothoff JW, Gruppen MP, Offringa M et al. Mortality and causes of death of end-stage renal disease in children: A Dutch cohort study. Kidney International 2002; 61: 621-9.

http://dx.doi.org/10.1046/j.1523$\underline{1755.2002 .00156 . x}$

17. Schaefer F, Mehls O. Endocrine and growth disturbances. In: Barratt TMAE, Harmon WE, eds. Pediatric Nephrology. 4th ed. Baltimore: Lippincott Williams \& Wilkins; 1999: 1197-230.

18. Hulstijn-Dirkmaat GM. Chronic renal failure in children: Psychological implications for development and family [Thesis]. Nijmegen: Katholieke Universiteit; 1995.

19. Cransberg K, Smits JMA, Offner G et al Kidney Transplantation without prior dialysis in children: The Eurotransplant Experience. American Journal of Transplantation 2006; 6(8):1858-64.

http://dx.doi.org/10.1111/j.1600$\underline{6143.2006 .01405 . x}$

20. El-Husseini AA, Foda MA, Osman YM, Sobh MA. Characteristics of long-term live-donor pediatric renal transplant survivors: a singlecenter experience. Pediatr Transplant 2006; 10(3): 288-93.

http://dx.doi.org/10.1111/j.1399$\underline{3046.2005 .00455 . x}$
21. Butani L, Perez RVEffect of pretransplant dialysis modality and duration on long-term outcomes of children receiving renal transplants. Transplantation 2011; 91(4):447-51.

22. Rizvi SAH, Zafar MN, Lanewala AA et al, Challenges in paediatric renal transplantation in developing countries. Current Opinion in Organ Transplantation 2009; 14(5):533-9. http://dx.doi.org/10.1097/MOT.0b013e32832ffb 41

23. Pape L, Offner G, Ehrich JHH et al. A single centre clinical experience in intensive care management of 104 pediatric renal transplantations between 1998 and 2002. Pediatric Transplantation 2004; 8(1): 39-43. http://dx.doi.org/10.1046/j.13973142.2003.00114.x

24. Coupe N, O'Brian M, Gibson P et al. Anesthesia for renal transplantation with and without epidural analgesia- a review of 7 yrs experience. Pediatric Anesthesia 2005; 15: 220-8 http://dx.doi.org/10.1111/j.14609592.2005.01426.x 